\title{
Experimental Assessment of Energy Performance and Emissions of a Residential Microcogenerator
}

\author{
Giovanni Angrisani ${ }^{1}$, Carlo Roselli ${ }^{1} \&$ Maurizio Sasso ${ }^{1}$, Peter Tzscheutschler ${ }^{2}$ \\ ${ }^{1}$ DING, Università degli Studi del Sannio, Piazza Roma 21, 82100 Benevento, Italy \\ ${ }^{2}$ Technische Universitat Munchen, Institute for Energy Economy \& Application Technology, Arcisstrasse 21, Munchen \\ 80333, Germany
}

Received: June 16, 2014 Accepted: June 30, 2014 Available online: August 4, 2014

doi:10.11114/set.v1i2.441

URL: http://dx.doi.org/10.11114/set.v1i2.441

\begin{abstract}
Microcogeneration systems, if correctly sized, managed and operated, can guarantee sensible primary energy savings and greenhouse gas emissions reductions in the residential sector. In this paper, the results of experimental tests carried out on a microcogenerator $(5.5 \mathrm{~kW}$ electric power and $14.8 \mathrm{~kW}$ thermal power) based on a natural gas fuelled internal combustion engine, integrated with a condensing boiler, have been analyzed. The tests were aimed at assessing the technical feasibility of the microcogeneration plant for residential applications, and at evaluating the possible energy and emissions savings it can achieve with respect to a benchmark scenario, based on separate "production" of electric and thermal energy. The tests have been performed at Institute for Energy Economy and Application Technology (IfE) of Technical University of Munich (Germany).

The test facility allowed to simulate the thermal energy requirements of a real residential application, represented by a Multi Family House consisting of 10 apartments, and to evaluate the energy flows of the conversion devices in actual operating conditions. Four type days, characteristic of Mediterranean climatic conditions, have been used to define space heating and domestic hot water user's requirements.

Experimental tests have been performed to implement energy and environmental analysis, comparing the system consisting of cogenerator and integration boiler with a reference system. Results showed that the former system can achieve a primary energy saving of about $6 \%$, and $\mathrm{CO}_{2}$ equivalent emissions reduction of about $12 \%$.

Finally, the algorithm defined by the European Directive on the promotion of high efficiency cogeneration has been implemented; it demonstrated that the primary energy saving is well above the limit value prescribed by the Directive. Therefore the cogeneration plant can access support mechanisms which can help to achieve the economic feasibility of the system, besides energy and environmental benefits.
\end{abstract}

Keywords: microcogenerator, experimental assessment, energy, greenhouse gas emissions, residential sector

\section{Introduction}

Nowadays buildings represent about $30-40 \%$ of final energy consumption in industrialized countries, overtaking other sectors such as industry and transportation. In the residential sector, energy consumption is mainly related to air-conditioning requirements, both in summer and winter, domestic hot water (DHW) production, and electric loads (lights, office automation, etc.).

Cogeneration is an alternative technology to the conventionally adopted solutions, which are the external grid for electricity requirements, and centralized or autonomous fossil fuelled boilers, to provide thermal energy for space heating and DHW.

The installation of small scale cogeneration systems (MCHP, Micro Combined Heat and Power) in buildings is obviously more expensive than conventional technologies, therefore MCHPs have to achieve lower primary energy requirements and operating costs reductions to be competitive, as well as lower greenhouse gas (GHG) emissions, to be supported and incentivized by Governments.

The present trend to shift from the centralized production to the distributed generation scenario is attracting considerable R\&D effort on experimental analysis and simulation of both MCHP (Roselli, Sasso, Sibilio, \& Tzscheutschler, 2011) and MCCHP (Micro Combined Cooling Heating and Power) systems (Angrisani, Roselli, Sasso, 
\& Tariello, 2014), with electric power lower than $15 \mathrm{~kW}$.

A key factor for distributed generation technologies, besides the high potential in reducing primary energy consumption and GHG emissions, is the decrease in energy losses related to: distribution of energy vectors over long distances (distributed generators provide energy on-site); operation at partial load of higher size equipment; use of intermediate equipment between generation and final use of energy. On the other hand, miniaturization of energy conversion devices often leads to an efficiency reduction (due to the so-called "size effect"), and this obviously has a negative effect on energy, economic and emissions performance of distributed generators (Angrisani, Roselli, \& Sasso, 2012).

The most attracting sectors for MCHP and MCCHP systems are currently tertiary and light commercial applications (Piacentino \& Cardona, 2008); nevertheless, in the brief-to-medium period, interesting market perspectives can be expected for residential buildings too (Pehnt et al., 2010), as the very high number of potential users and the on-going increase of available products could in few years determine cumulative installed powers much higher than in the tertiary sector.

For example in single family houses, the aim of R\&D activities on MCHP is to gradually substitute natural gas boilers with devices having similar characteristics of safety, ease of use and installation, but which are capable of producing both thermal and electric energy; generally, technical feasibility can be achieved only if cogenerated heat is never dissipated and electricity is produced during peak hours, when the purchase cost from the grid is higher.

Nowadays, reciprocating internal combustion engine based systems represent the most widespread technology for small scale cogeneration, due to several advantages, such as small installation space, high electric and thermal efficiencies, quite low noise and vibrations, low maintenance cost, low specific investment cost and long life service. The Stirling engine, with respect to internal combustion engines, is not fully developed yet, and it is not widely used, due to low electric efficiency, high pressure level of working gas, high specific investment cost and quite long warm-up periods (Angrisani et al., 2012).

To achieve energy and greenhouse gas savings, microcogeneration systems need to be correctly sized, managed and operated. To this aim, University of Sannio, in cooperation with the Institute for Energy Economy and Application Technology (IfE) of Technical University of Munich (Germany), carried out experimental tests aimed at assessing the performance of an MCHP system in a residential building. The microcogenerator is based on a natural gas fuelled internal combustion engine; it produces $5.5 \mathrm{~kW}$ electric and $14.8 \mathrm{~kW}$ thermal power, and it is integrated with a natural gas condensing boiler. The tests were aimed at assessing the technical feasibility of a microcogeneration plant for residential applications, and at evaluating the possible energy and emissions savings it can achieve with respect to typically adopted technologies, based on separate "production" of electric and thermal energy. Results of the tests allowed to evaluate the daily and annual energy performance of the combined generation system installed at a reference building, and to evaluate the potential of energy consumption and emissions reductions with respect to a benchmark scenario.

\section{Method}

\subsection{Building Definition}

The MCHP unit is assumed to be installed at a multifamily house (MFH) consisting of 10 apartments, located in Naples, a city in the South of Italy with 1034 degree days.

Table 1. Building data

\begin{tabular}{cc}
\hline Floor area $\left[\mathrm{m}^{2}\right]$ & 1216 \\
Heated volume $\left[\mathrm{m}^{3}\right]$ & 3176 \\
Mean headroom [m] & 2.61 \\
Number of storeys [-] & 4 \\
Surface to Volume ratio [-] & 0.447 \\
Construction period & $1961-1975$ \\
Number of occupants [-] & 30 \\
Space heating thermal energy requirement $\left[\mathrm{kWh} / \mathrm{m}^{2} / \mathrm{year}\right]$ & 46.5 \\
DHW thermal energy requirement $[\mathrm{kWh} / \mathrm{day}]$ & 42.9 \\
\hline
\end{tabular}

In Table 1, characteristic data and energy requirement of the investigated building are reported, while in Table 2 heat transfer properties of the opaque and transparent devices of the building envelope are shown, namely surface, overall 
heat transfer coefficient $U$ and solar gain $g$.

It was not possible to perform one year-long experimental tests, therefore the type days approach was used: four type days, which represented the different climatic conditions normally occurring at the installation site, were used for testing purposes. Energy and emission assessments were then extended on an annual basis, considering the number of yearly occurrences of each type day.

Table 2. Properties of the building envelope

\begin{tabular}{ccccccc}
\hline & \multicolumn{3}{c}{ Opaque devices } & \multicolumn{3}{c}{ Windows } \\
& Roof & External walls & Cellar & North & South & East/West \\
\hline Surface $\left[\mathrm{m}^{2}\right]$ & 304 & 637 & 304 & 69 & 76 & 14 \\
$\mathrm{U}\left[\mathrm{W} / \mathrm{m}^{2} \mathrm{~K}\right]$ & 2.30 & 1.20 & 0.297 & 2.83 & 2.83 & 2.83 \\
$\mathrm{~g}[-]$ & - & - & - & 0.76 & 0.76 & 0.76 \\
\hline
\end{tabular}

The following type days were defined:

-1: winter (January and February);

-2: intermediate with space heating requirements (November 15 - December 31; March);

-3: intermediate without space heating requirements (April, May and September 16 - November 14);

-4: summer (June 1 - September 15).

Type days were defined considering the period of allowed operation of the space heating system, specified by Italian legislation (November 15th to March 31st), as well as hourly temperature values. No differences were defined between weekends and weekdays.

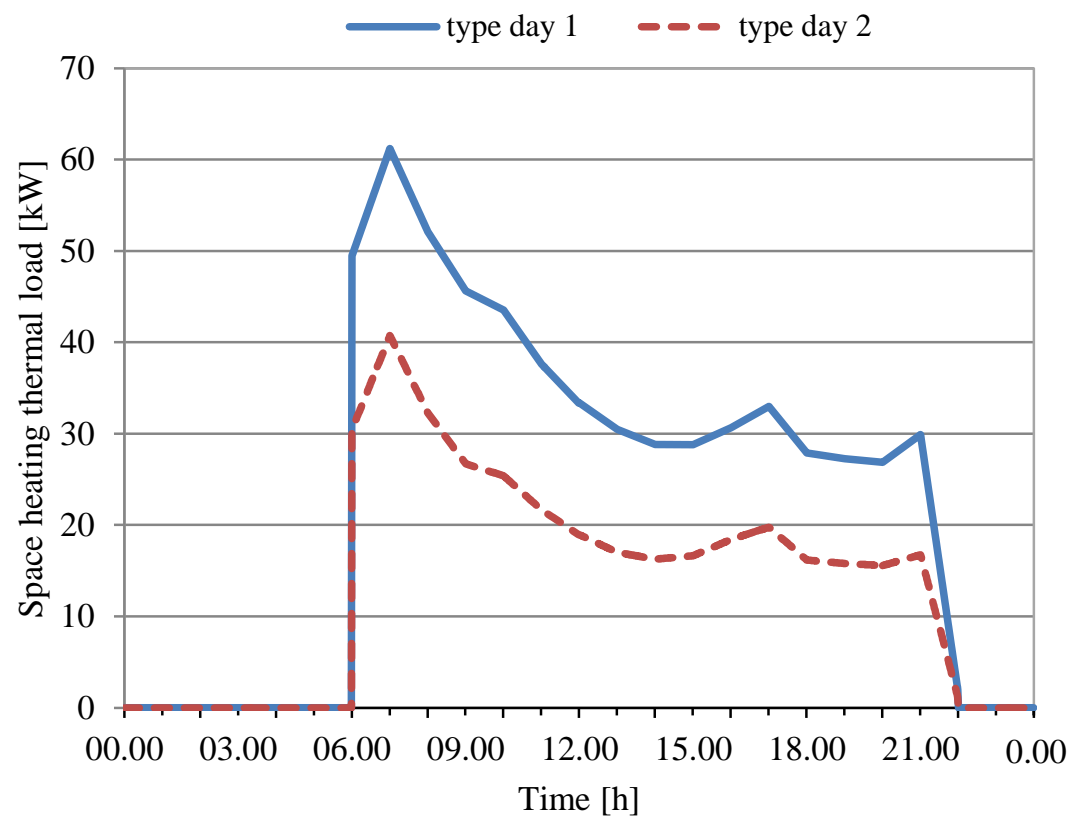

Figure 1. Space heating thermal load profiles

Thermal load profile for space heating requirements (type days 1 and 2) were defined by means of dynamic simulations of the building through TRNBuild interface (TRNSYS 17, 2010); they are shown in Figure 1. The typical early morning peak, when a very high thermal power is required to increase the indoor air temperature to the set-point value of $20{ }^{\circ} \mathrm{C}$, was obtained. The load then reduces during the day, with a minimum value at about $14.00 \mathrm{~h}$, when solar gain is maximum. 


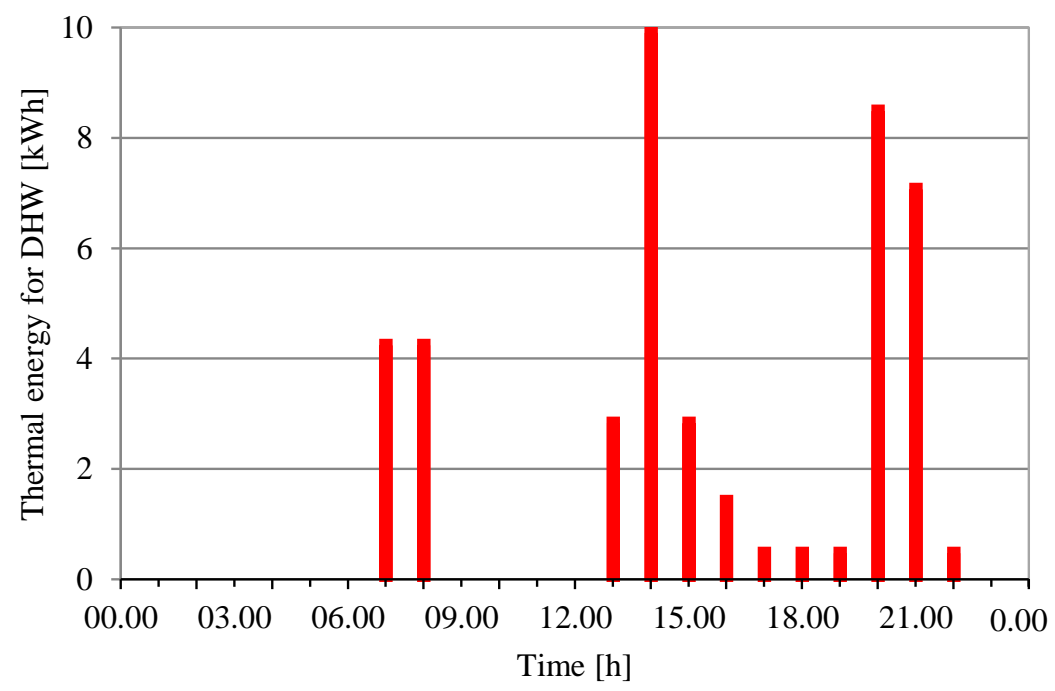

Figure 2. Thermal energy requirements for DHW (same profile for type days 2 and 3)

Thermal energy demand for DHW, shown in Figure 2 (the same profile for type days 2 and 3, the profile for the other type days is not shown for major clarity), has been defined considering a requirement of $401 /$ (day·occupant).

\subsection{Performance assessment}

For the MCHP system, the following energy performance parameters were used:

$$
\begin{gathered}
\eta_{e l}=\frac{E_{e l, C H P}}{E_{p, C H P}} \\
\eta_{t h}=\frac{E_{t h, C H P}}{E_{p, C H P}} \\
P E R=\frac{E_{e l, C H P}+E_{t h, C H P}}{E_{p, C H P}}
\end{gathered}
$$

where $E_{e l, C H P}, E_{t h, C H P}$ and $E_{p, C H P}$ are electric energy output, thermal energy output and primary energy input of the MCHP system and $\eta_{e l}, \eta_{t h}$ and PER (Primary Energy Ratio) are electric, thermal and overall efficiency, respectively.

Energy and emissions performance of the proposed system (MCHP and integration boiler, Proposed System, PS) were compared, considering equal final energy provided to the user, with a reference scenario (Traditional System, TS), based on separate "production" of electric and thermal energy, which is conventionally adopted for energy demands supply. The TS, in each type day, has to ensure the same space heating and DHW demands provided to the building by the PS and it has to draw from the electric grid the same amount of electricity generated by the MCHP.

The assumed TS consisted of:

- a condensing natural gas fuelled boiler, supplying thermal energy for space heating and DHW, with a nominal efficiency $\eta_{t h, \text { ref }}=102 \%$, based on LHV (Lower Heating Value);

- national Italian electric grid, with an average efficiency $\eta_{e l, r e f}=42 \%$, including transmission and distribution losses (Angrisani et al., 2014).

More details about the hydraulic schemes of both PS and TS are given in Section 2.3.

The energy comparison between PS and TS was performed by means of the FESR parameter (Fuel Energy Saving Ratio), defined as (Angrisani et al., 2014):

$$
F E S R=\frac{E_{p}^{T S}-E_{p}^{P S}}{E_{p}^{T S}}
$$


where $E_{p}^{T S}$ and $E_{p}^{P S}$ are the primary energy input of TS and PS, respectively.

For the emissions comparison the equivalent $\mathrm{CO}_{2}$ avoided emissions was used:

$$
\Delta C O_{2, e q}=\left(m_{\mathrm{CO}_{2, e q}}^{T S}-m_{\mathrm{CO}_{2}, e q}^{P S}\right) / m_{\mathrm{CO}_{2, e q}}^{T S}
$$

where the emissions of PS $\left(m_{\mathrm{CO}_{2}, e q}^{P S}\right)$ and TS $\left(m_{\mathrm{CO}_{2}, q}^{T S}\right)$ were evaluated considering (Angrisani et al., 2014):

- equivalent carbon dioxide specific emission factors of Italian electric grid (ratio of equivalent $\mathrm{CO}_{2}$ emissions to electric energy output) equal to $573 \mathrm{~g}_{\mathrm{CO} 2, \mathrm{eq}} / \mathrm{kWh}_{\mathrm{el}}$;

- equivalent carbon dioxide emission factor of natural gas (ratio of equivalent $\mathrm{CO}_{2}$ emissions to primary energy input) equal to $207 \mathrm{~g}_{\mathrm{CO} 2, \mathrm{eq}} / \mathrm{kWh}_{\mathrm{p}}$.

A further analysis was based on the Directive on the promotion of cogeneration (Directive 2004/8/EC), which defines the PES (Primary Energy Saving) index, as:

$$
P E S=1-\frac{E_{p, C H P}}{\frac{E_{e l, C H P}^{*}}{\eta_{e l, r e f}}+\frac{E_{t h, C H P}}{\eta_{t h, r e f}}}
$$

$E_{e l, C H P}^{*}$ is the cogenerated electricity, and it coincides with the overall production from the MCHP ( $\left.E_{e l, C H P}\right)$ if the PER is higher than a limiting value (75\% for internal combustion engine based cogenerators). The symbols $\eta_{e l, r e f}$ and $\eta_{t h, \text { ref }}$ are the harmonised efficiency reference values for separate production of electricity and heat, respectively. European Commission provides a method to evaluate harmonised values for $\eta_{e l, \text { ref }}$ and $\eta_{t h \text {,ref }}$ (Commission Decision of 21 December 2006, Commission implementing decision of 19 December 2011). In particular, $\eta_{e l, \text { ref }}$ depends on factors such as: installation year of the cogeneration unit, climatic conditions (average ambient temperature), fuel used and a correction factor ' $p$ ', which depends on the share of electricity used on-site and on the voltage level, and which takes into account the avoided grid losses due to decentralized production. On the other hand, $\eta_{t h, \text { ref }}$ depends on the fuel and the way the available thermal energy is exploited (direct use of exhaust gases or "production" of steam/hot water).

With respect to the MCHP unit considered, the evaluation of PES was carried out considering that:

- the prime mover is a reciprocating internal combustion engine;

- thermal energy recovered by the MCHP is used to produce hot water;

- the fuel is natural gas;

- the installation year is 2014 ;

- the average ambient temperature is $16.04{ }^{\circ} \mathrm{C}\left(0.104 \%\right.$-point reduction of $\eta_{e l, \text { ref }}$ with respect to a reference temperature of $15{ }^{\circ} \mathrm{C}$ );

- the electricity is produced at low voltage ( $<400 \mathrm{~V}, p=0.860$ for electricity consumed on-site, $p=0.925$ for exported electricity).

With the above listed information, the Commission Decision provides $\eta_{t h, r e f}=90 \%$ and a base value of $\eta_{e l, r e f}=52.5 \%$.

When the electric rated power of CHP unit is less than $50 \mathrm{~kW}$, the $P E S$ has to be higher than zero in order to achieve the "high efficiency cogeneration" qualification. High efficiency cogeneration units can access several benefits, such as: distribution priority, subsidies on gas price, net metering (for CHP units with electric power lower than $200 \mathrm{~kW}$ ), revenues related to white certificates (energy efficiency credits) mechanism, investment subsidies (guarantee or revolving funds, public grants) up to $40 \%$ of the investment cost for plants with electric power up to $200 \mathrm{~kW}$. These incentives can promote the economic feasibility of MCHP systems with respect to traditional technologies. 


\subsection{The Test Facility}

The test facility allows to simulate thermal energy demands for space heating and DHW of a residential building (MFH) and to evaluate energy flows of energy conversion devices in actual operating conditions.

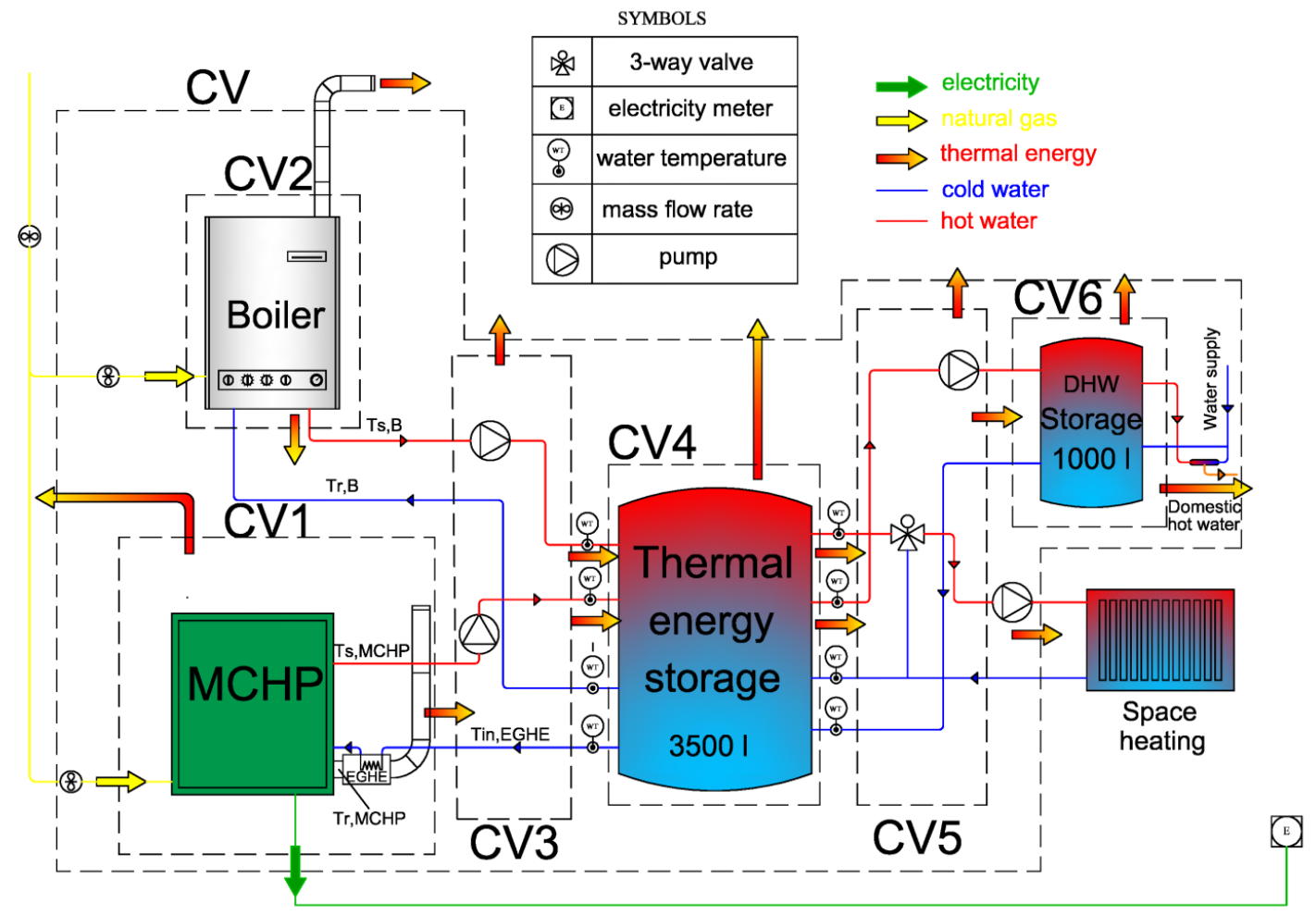

Figure 3. The test facility

Figure 3 shows the layout of the test facility and the different control volumes (CV) defined for the energy balances.

The following main components are present (Arndt, Mauch, Mühlbacher, Tzscheutschler, \& Geiger, 2008):

- a MCHP (CV1);

- a condensing boiler for thermal integration (CV2), fuelled by natural gas and with a nominal thermal efficiency of $102 \%$, based on LHV;

- a 35001 thermal energy storage (CV4);

- a 10001 DHW storage (CV6);

- a simulator of thermal energy demands for space heating of the building;

- a simulator of thermal energy demands for DHW;

- auxiliaries (pumps, 3-way valves, etc.);

- sensors for water temperature, water and natural gas mass flow rates.

CV3 contains the pipes between the energy conversion devices (MCHP and boiler) and the main thermal storage (CV4), while CV5 contains the pipes between CV4 and energy demands (space heating and DHW storage). The overall control volume (CV) contains the whole test facility.

The space heating simulator consists of several vessels with different capacities, which simulate thermal loads as well as thermal inertia and losses of radiators and distribution pipes within the building. In particular, energy related to thermal loads and losses is simulated by means of heat exchangers interacting with a cooling circuit. Thermal energy demands for DHW are simulated by means of taps, drawing water from the related 10001 storage.

The MCHP is heat-led, i.e. the unit follows thermal energy demands of the buildings, while cogenerated electricity can be consumed on-site or exported to the grid.

When water temperature inside the main storage falls below the set-point value, the MCHP starts providing thermal energy to CV4; when water temperature in the storage is higher than the set-point, the MCHP stops. When water temperature entering the $\mathrm{MCHP}\left(T_{r, M C H P}\right)$ is higher than $65^{\circ} \mathrm{C}$, the MCHP also stops, as this quite high value of return 
temperature points out a very low thermal demand from the user.

When water temperature required by the heating circuit is higher than water in the storage and the MCHP is already operating, the integration boiler activates providing thermal energy shortage.

Table 3. Nominal characteristics of the MCHP

\begin{tabular}{cc}
\hline $\begin{array}{c}\text { Engine } \\
\text { Fuel }\end{array}$ & $\begin{array}{c}\text { Internal combustion engine } \\
\text { Natural gas }\end{array}$ \\
\hline$P_{e l}[\mathrm{~kW}]$ & 5.5 \\
$P_{t h}[\mathrm{~kW}]$ & 14.8 \\
$P_{p}[\mathrm{~kW}]$ & 20.5 \\
$\eta_{e l}[-]$ & 0.27 \\
$\eta_{t h}[-]$ & 0.72 \\
$P E R[-]$ & 0.99 \\
\hline
\end{tabular}

In Table 3, the nominal characteristics of the tested MCHP are reported. The unit is equipped with an optional heat exchanger (Exhaust Gas Heat Exchanger, EGHE in Figure 3), externally installed, which allows a further thermal energy recovery from the condensation of water in exhaust gases, which have a temperature of about $150{ }^{\circ} \mathrm{C}$ at the exit of the MCHP; by means of the EGHE, with a water temperature from the storage at $35^{\circ} \mathrm{C}$, exhaust gases can be cooled down to about $55{ }^{\circ} \mathrm{C}$, condensing about half the water contained in the gases, similarly to a condensing boiler.

The recovered latent heat from water condensation, which adds to thermal recovery from engine and from electric generator cooling, allows obtaining very high values of thermal efficiency and PER.

The TS, consisting of a condensing natural gas fuelled boiler and the national Italian electric grid, has a layout similar to that of Fig. 3, the differences are related to the absence of the control volumes CV1, CV3 and CV4. The boiler in TS is directly connected, by means of CV5, to the DHW storage and to the space heating circuit.

\section{Results}

In Figure 4, the supply and return water temperature from the MCHP ( $T_{s, M C H P}$ and $T_{r, M C H P}$, respectively), supply water temperature from the boiler $\left(T_{s, B}\right)$, as well as the temperature of water entering the EGHE $\left(T_{i n, E G H E}\right)$ are shown for type day 1. Starting from about 13:30, even if thermal power provided by the MCHP is lower than user's requirement, an intermittent operation of the cogenerator is established. This is due to the hydraulic layout of the test facility (parallel connection of MCHP and boiler to the main storage). Furthermore, the integration boiler provides a thermal power of at least $25 \mathrm{~kW}$, which is almost enough to cover user's demands during the periods with low energy requirements; this causes an increase of $T_{r, M C H P}$ and the consequent intermittent operation of the MCHP. This anomalous circumstance does not determine a significant reduction of daily energy performance of the microcogenerator, as the operation stoppages are quite brief (about 70 minutes per day).

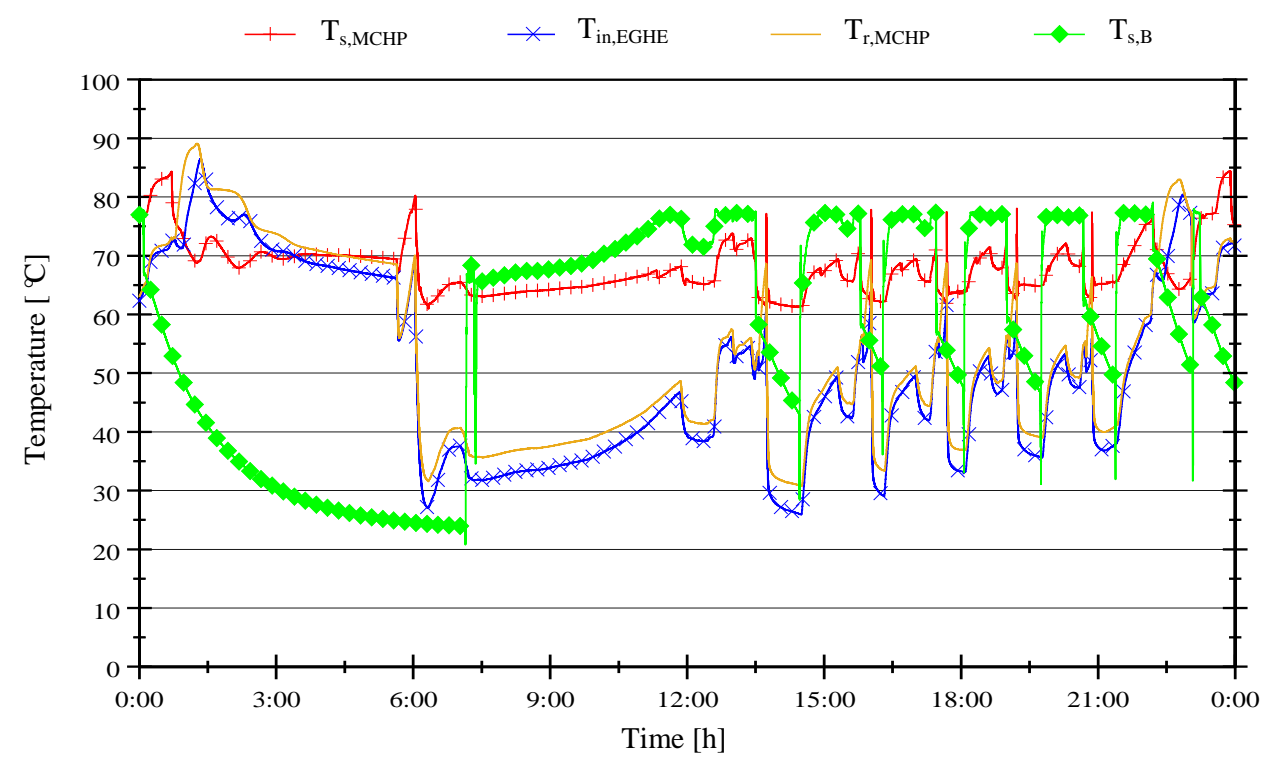

Figure 4. Temperatures for type day 1 


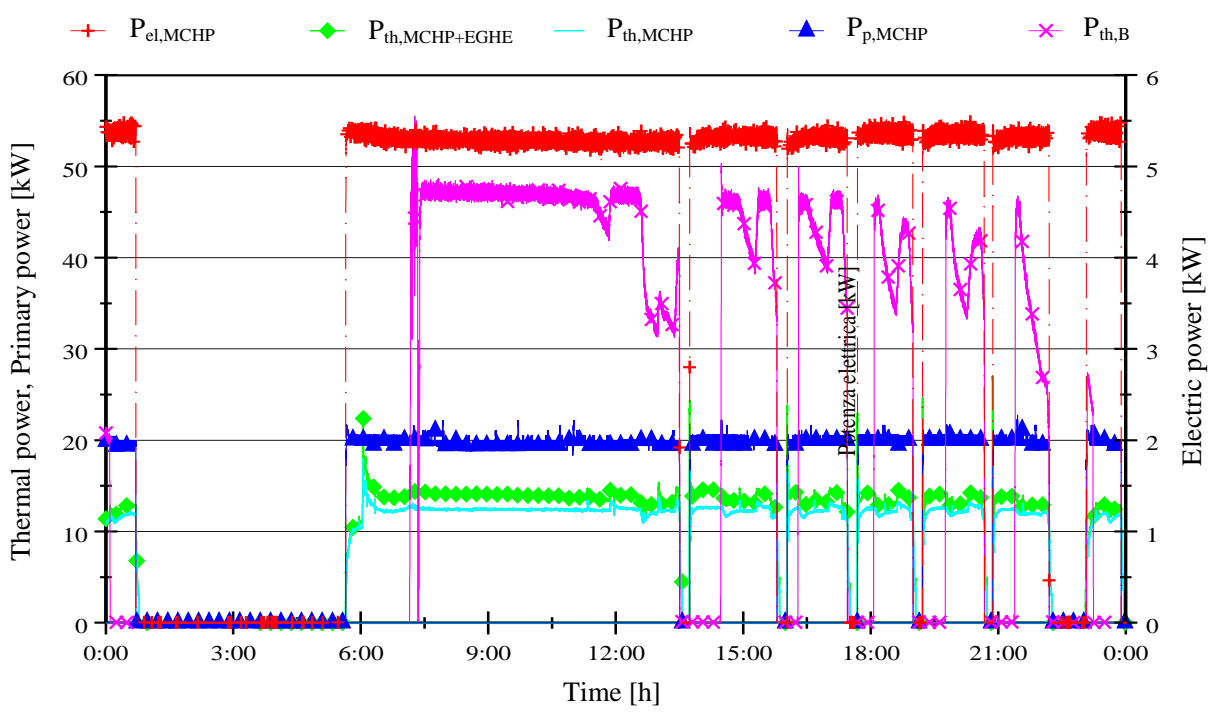

Figure 5. Thermal, electric and primary powers for type day 1

Thermal power supplied by the MCHP (with and without the contribution from the EGHE) and by the boiler, as well as electric power output and primary power input to the MCHP are shown, for type day 1 (winter) in Figure 5. The boiler provides a very high thermal power in the early morning, when there is high thermal energy demand for space heating and DHW. The MCHP provides net electric power output constantly equal to about $5.3 \mathrm{~kW}$, as it is a non-modulating unit; the self-consumption of MCHP auxiliaries is about $200 \mathrm{~W}$.

The EGHE provides a thermal power of about $2 \mathrm{~kW}$, and this contribution rises when $T_{i n, E G H E}$ reduces (Figure 4), as the condensation effect is enhanced.

As regards primary power input to the MCHP and to the boiler, the temperature and pressure of natural gas are measured, in order to correlate its actual LHV to the standard value. An average value of $10.0 \mathrm{kWh} / \mathrm{Nm}^{3}$ has been assumed for the LHV.

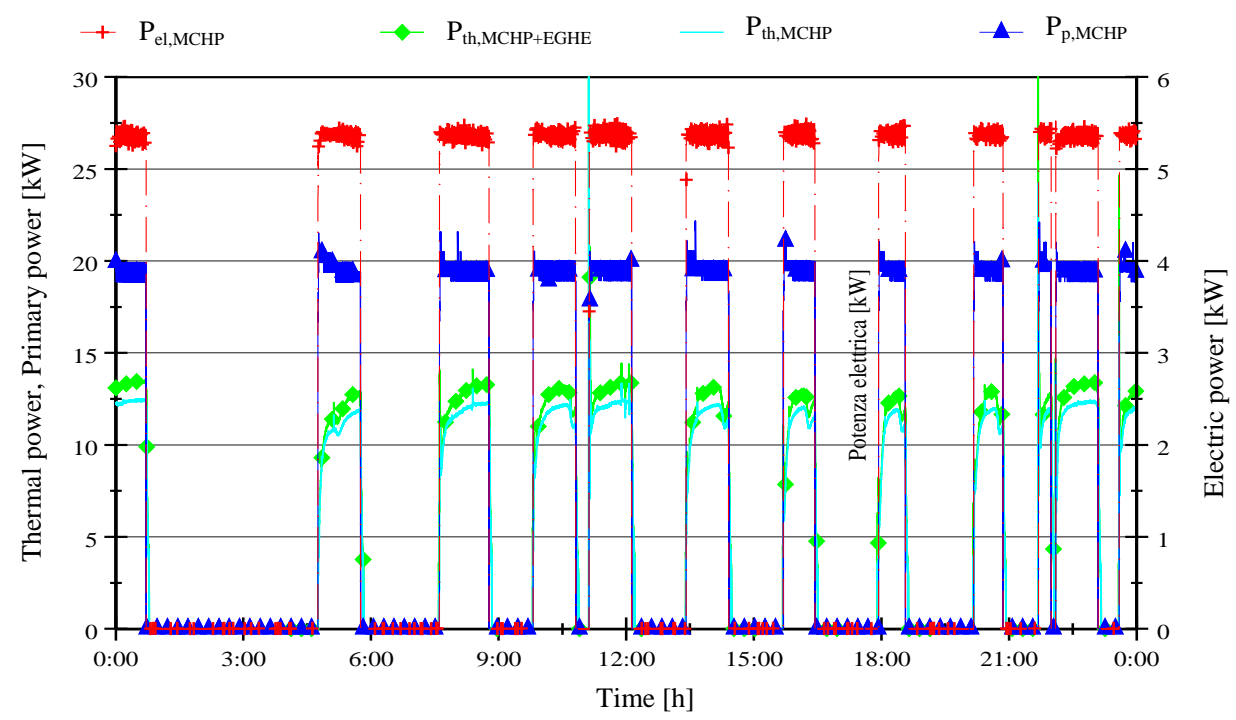

Figure 6. Thermal, electric and primary powers for type day 4

A similar analysis has been also performed for the other type days. In Figure 6 the main electric and thermal power for 
type day 4 (summer) are shown. During summer, the MCHP can provide the whole thermal energy required, as user's demand is related to DHW only, and the boiler never activates.

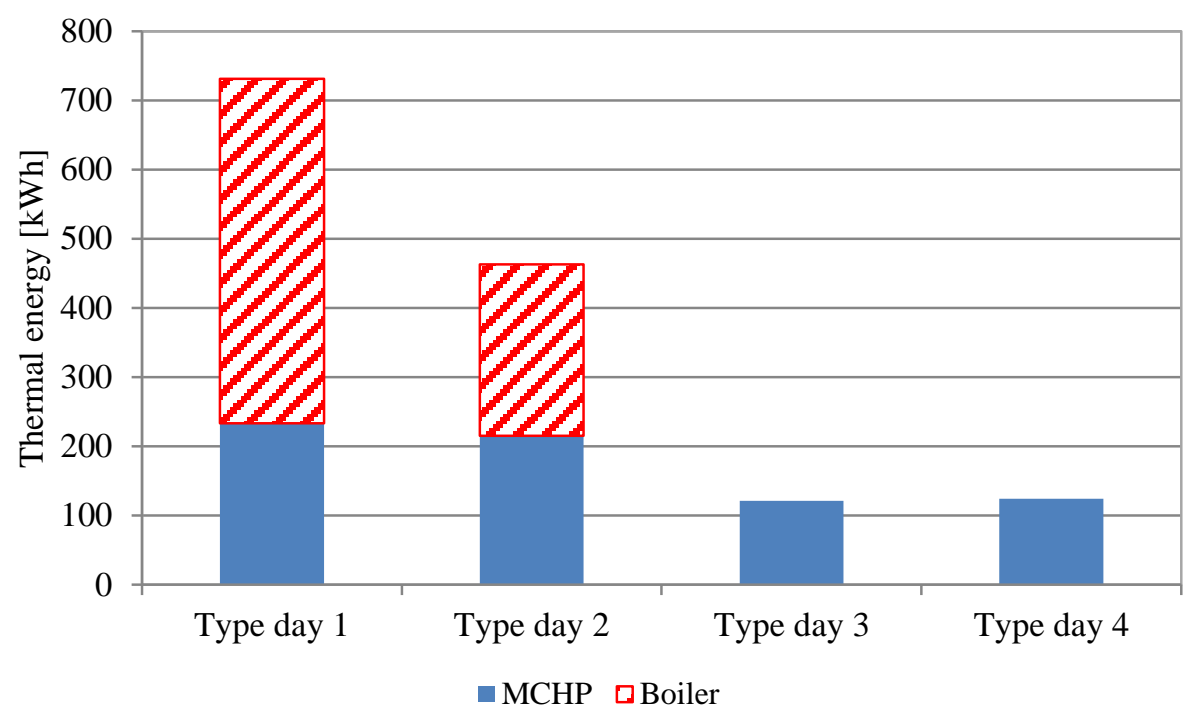

Figure 7. MCHP and boiler contribution to thermal energy demands for each type day

In Figure 7 the contribution of the MCHP and of the boiler to thermal energy requirements of the user for each type day is shown. The MCHP provides about $31.9 \%$ and $46.4 \%$ of the required thermal energy during type day 1 and 2 , respectively, and about $48.2 \%$ on an annual basis. Therefore, the MCHP is not the main contributor to the thermal energy demand, especially during winter, as its size was chosen to maximize the number of operating hours during activation period of the space heating plant (November 15th to March 31st, type days 1 and 2). In fact, nominal thermal power of the microcogenerator $(14.8 \mathrm{~kW})$ is lower than the minimum thermal power required for space heating purposes during type day 2 (Figure 1).

Table 4. Daily energy balance for the MCHP in each type day

\begin{tabular}{ccccc}
\hline & Type day 1 & Type day 2 & Type day 3 & Type day 4 \\
\hline$E_{p}[\mathrm{kWh}]$ & 336 & 300 & 185 & 190 \\
$E_{e l}[\mathrm{kWh}]$ & 90.7 & 81.0 & 50.0 & 51.3 \\
$E_{t h}[\mathrm{kWh}]$ & 233 & 215 & 121 & 124 \\
$t_{M C H P}[\mathrm{~h}]$ & 16.9 & 15.2 & 9.40 & 9.66 \\
$\eta_{e l}[-]$ & 0.270 & 0.270 & 0.270 & 0.270 \\
$\eta_{t h}[-]$ & 0.693 & 0.717 & 0.654 & 0.653 \\
$P E R[-]$ & 0.963 & 0.987 & 0.924 & 0.923 \\
\hline
\end{tabular}

In Table 4, the main energy flows related to the MCHP (CV1) on a daily basis are reported. Electric efficiency is equal to the nominal value, as the related transient losses are negligible, while thermal efficiency, and accordingly the PER, are lower than the nominal values. In particular, the lower values of $\eta_{t h}$ and PER are obtained during type days 3 and 4, due to the thermal losses related to cycling operation of the MCHP (higher number of start and stop, Figure 6, with respect to winter type day, Figure 5). The reduction of thermal energy requirements in type days 3 and 4 determines an abatement of MCHP operating hours $\left(t_{M C H P}\right.$, Table 4$)$ and the disappearance of the boiler energy contribution (Figure 7).

The MCHP achieves efficiencies values very similar to the nominal ones (Table 3) during type days 1 and 2, when the space heating thermal load allows the cogenerator to work at stationary full thermal load conditions for several continuative hours. The best performance are achieved in type day 2 (intermediate with space heating requirements), as the contribution of the boiler is lower than in type day 1 (Figure 7), therefore a reduction of the intermittent operation of the MCHP is obtained. 
On an annual basis, the PER of the MCHP is equal to $95.5 \%$, with more than 4300 overall operating hours per year, which is a very favourable value for residential small scale cogeneration.

Table 5. Annual energy balance for each control volume

\begin{tabular}{cccccccc}
\hline & CV1 & CV2 & CV3 & CV4 & CV5 & CV6 & CV \\
\hline$E_{p}[\mathrm{MWh}]$ & 85.9 & 47.8 & - & - & - & - & 133.7 \\
$E_{\text {th, }, \text { }}[\mathrm{MWh}]$ & - & - & 107.1 & 101.6 & 95.5 & 31.7 & - \\
$E_{\text {th, out }}[\mathrm{MWh}]$ & 58.4 & 48.7 & 101.6 & 95.5 & 87.6 & 16.8 & 73.4 \\
$E_{\text {th loss }}[\mathrm{MWh}]$ & 4.3 & - & 5.50 & 6.10 & 7.90 & 14.9 & 38.6 \\
$E_{\text {el }}[\mathrm{MWh}]$ & 23.2 & - & - & - & - & - & 23.2 \\
\hline
\end{tabular}

In Table 5 the annual energy balance for the control volumes defined in Figure 1 are reported. $E_{p}$ represents primary energy input, $E_{t h, i n}$ is thermal energy input, $E_{t h, o u t}$ is thermal energy output, $E_{t h \text {,loss }}$ is thermal energy lost and $E_{e l}$ is electric energy output. The boiler (CV2), thanks to the condensation of exhaust gases, provides a thermal energy output higher than primary energy input, as the latter is based on LHV, not HHV (Higher Heating Value). Therefore, no thermal losses have been assumed for CV2, even if they are higher than zero but impossible to be evaluated within the test facility used for the tests.

Regarding CV6, $E_{t h, l o s s}$ takes into account thermal energy losses of both the DHW storage and of the recirculation circuit, which is a closed loop, connected to the DHW tank, where the fluid is continuously pumped, so that even the users most distant from the tank itself can instantly have hot water available at any time. As regards the overall control volume $(\mathrm{CV}), E_{t h, o u t}$ is the sum of thermal energy for DHW ( $E_{t h, o u t}$ from CV6) and for space heating ( $E_{t h}^{S H}=56.6 \mathrm{MWh}$ ).

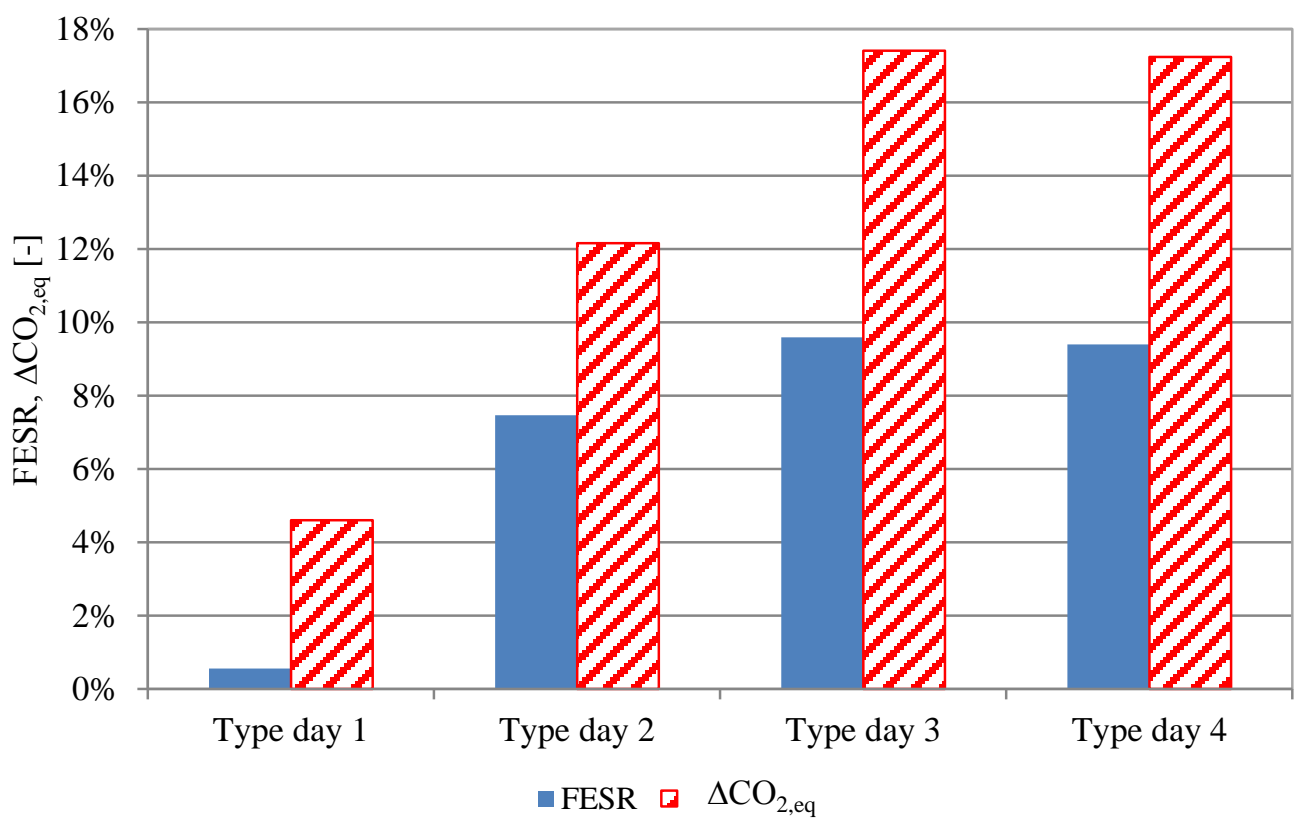

Figure 8. FESR and $\triangle C O_{2, e q}$ for each type day.

To apply Eq. 4, the primary energy input of PS ( $\left.E_{p}^{P S}\right)$ and TS $\left(E_{p}^{T S}\right)$ have to be evaluated with the following equations:

$$
E_{p}^{P S}=E_{p}^{C V 1}+E_{p}^{C V 2}
$$




$$
E_{p}^{T S}=\frac{E_{e l}^{C V 1}}{\eta_{e l, r e f}}+\frac{E_{t h, i n}^{C V 6}+E_{t h}^{S H}}{\eta_{t h, r e f}}
$$

Figure 8 shows the FESR and $\triangle C O_{2, e q}$ parameters for the four type days. Both parameters are positive for any type day, and they vary from a minimum for type day $1(0.6 \%$ and $4.6 \%$, respectively) to a maximum for type days 3 and 4 (about $9 \%$ and $17 \%$, respectively). The low values of the energy and emissions parameters during the winter type day are due to the very high contribution of the condensing boiler in the PS to the thermal demands of the user, while during type days 3 and 4 the boiler is always switched off, and the MCHP achieves the highest energy saving. On an annual basis, the $F E S R$ is about $5.8 \%$, while the $\triangle C O_{2, e q}$ is about $11.4 \%$.

These results justify the support given to cogeneration by European Union, according to which a wide diffusion of cogeneration could significantly contribute to the greenhouse gas emissions reduction towards 2020 .

As regards the application of the European Directive (Directive 2004/8/EC), the PER of the MCHP on annual basis is about $95.8 \%$, which is higher than the limit value for internal combustion engine based systems $(75 \%)$; therefore $E_{e l, C H P}^{*}=E_{e l, C H P}$ in equation 6.

Figure 9 shows the $P E S$ as a function of the ratio between electricity consumed on-site to overall production from the MCHP. The constraint defined by the Directive $(P E S>0)$ is abundantly met by the investigated MCHP, even in the worst case where no electricity from the cogenerator is consumed within the simulated building. The PES rises with the share of electricity consumed on-site, as the correction factor ' $p$ ' defined by European Directive for $\eta_{e l, \text { ref }}$ is lower if electric energy from the MCHP is consumed on-site, to take into account the avoided grid losses related to electricity distribution. Therefore, the investigated microcogenerator is a high efficiency cogeneration unit and it can access the several benefits defined in section 2.2 .

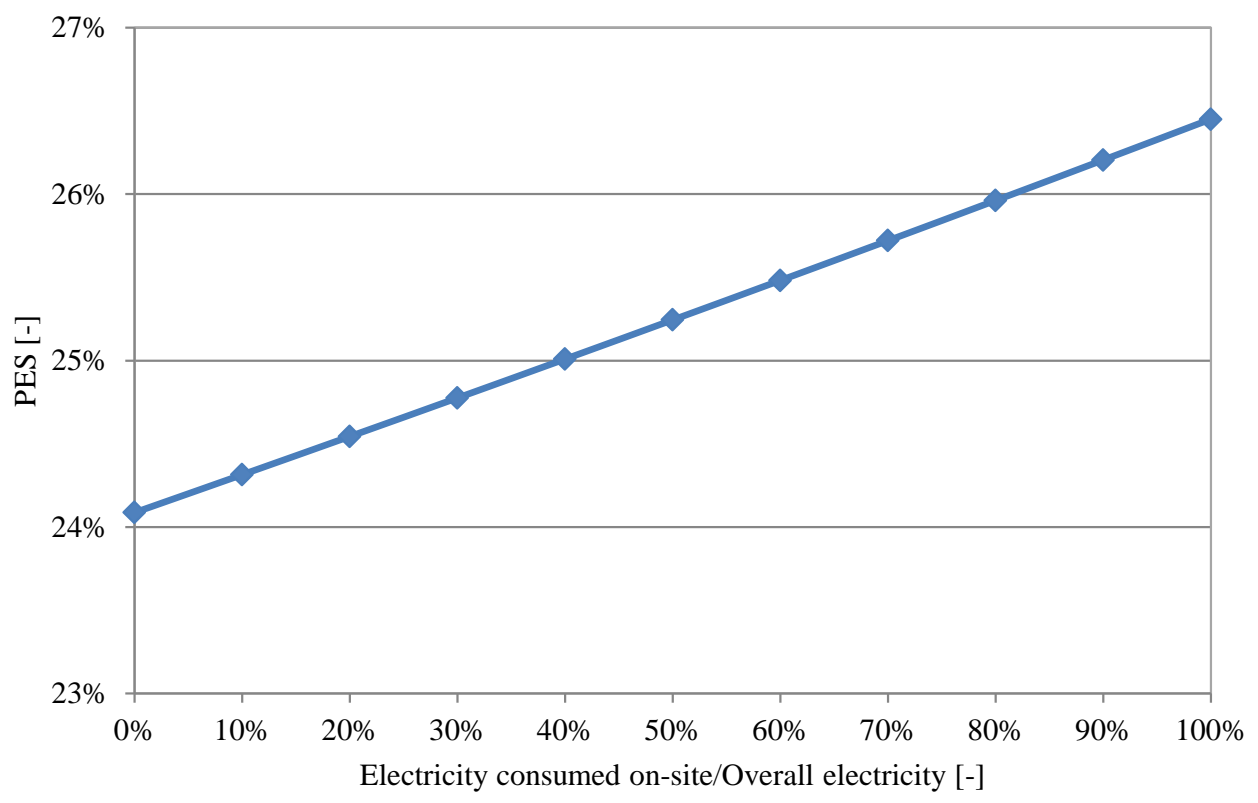

Figure 9. PES as a function of the ratio between electricity consumed on-site to overall production from the MCHP

\section{Discussion}

In this paper, a microcogenerator for residential users have been investigated at a test facility of the Institute for Energy Economy and Application Technology (IfE) of Technical University of Munich (Germany). It is based on a natural gas fuelled internal combustion engine, with $5.5 \mathrm{~kW}$ and $14.8 \mathrm{~kW}$ electric and thermal power, respectively, and it is integrated with a condensing boiler. The test facility allows to simulate thermal energy demands for space heating and domestic hot water purposes of a multifamily house consisting of ten apartments, and to evaluate the main energy flows of the energy conversion devices in actual operating conditions.

The performance assessment of the microcogeneration plant has been performed by means of experimental tests for four type days (winter, intermediate - with and without space heating demands - and summer), representing the climatic conditions of the installation site (Naples, Italy). 
The energy analysis on a daily basis showed electric, thermal and overall efficiencies of the MCHP very close to the nominal values; the condensing boiler strongly contributed to user's thermal energy requirements during winter type day, due to the high demands for space heating purposes. Boiler contribution went zero when thermal energy was required for domestic hot water only.

The parallel connection of the MCHP and of the boiler to the main thermal energy storage did not allow an optimal management of the microcogenerator. In fact the boiler provided thermal power almost enough to cover user's needs during low demand hours; this caused an increase of return temperature from the storage to the MCHP and its consequent intermittent operation. Nevertheless, this circumstance did not determine a significant reduction of energy performance of the microcogenerator, but it could determine a reduction of the technical life of the device. Further tests should be performed to assess the performance of the system with alternative hydraulic schemes, as those described in Arndt et al., 2007.

Experimental data have been used to perform an energy and greenhouse gas emissions analysis, with a comparison between the microcogeneration plant (proposed system), with a reference traditional system, consisting of a natural gas fuelled condensing boiler and the national electric grid. The Fuel Energy Saving Ratio (FESR) and the equivalent $\mathrm{CO}_{2}$ avoided emissions $\left(\triangle C \mathrm{O}_{2, e q}\right)$ are the parameters used for the energy and emissions analysis, respectively.

Both parameters were positive for any type day: the FESR varied from a minimum of $0.5 \%$ to a maximum of $9 \%$, while the $\Delta C O_{2, e q}$ ranged from $4.6 \%$ to $17 \%$. On an annual basis, the $F E S R$ was about $5.8 \%$, while the $\triangle C O_{2, e q}$ was about $11.4 \%$.

Finally, the calculation method defined by the European Directive on the promotion of cogeneration was applied. The reference harmonised values of thermal and electric efficiency were calculated; the results showed that the Primary Energy Saving (PES) was positive (above 24\%), and it raised with the ratio between electricity consumed on-site to overall production from the MCHP. Therefore, the experimentally tested device is a high efficiency cogeneration system, and it can access all support mechanisms defined by European and Italian governments to promote the economic feasibility of this technology.

In conclusion, cogeneration is an energy efficiency measure with a high potential of energy consumption and emissions reductions also in residential applications (microcogeneration), provided that recovered thermal energy is completely used and never wasted.

\section{Nomenclature}

E

FESR

$\mathrm{g}$

LHV

$\mathrm{m}_{\mathrm{CO}_{2}, \text { eq }}$

$\mathrm{p}$

$\mathrm{P}$

PER

PES

$\mathrm{t}$

$\mathrm{T}$

$\mathrm{U}$

$\Delta \mathrm{CO}_{2, \mathrm{eq}}$

$\eta$

CV

DHW

EGHE

GHG

MCHP

MCCHP energy, kWh

Fuel Energy Saving Ratio, -

solar gain, -

Lower Heating Value, $\mathrm{kWh} / \mathrm{Nm}^{3}$

mass of equivalent $\mathrm{CO}_{2}, \mathrm{~kg}$

correction factor, -

power, $\mathrm{kW}$

Primary Energy Ratio, -

Primary Energy Saving, -

time, $\mathrm{h}$

temperature, ${ }^{\circ} \mathrm{C}$

overall heat transfer coefficient, $\mathrm{W} \mathrm{m}^{-2} \mathrm{~K}^{-1}$

equivalent $\mathrm{CO}_{2}$ avoided emissions, -

efficiency, -

Control Volume

Domestic Hot Water

Exhaust Gas Heat Exchanger

Greenhouse Gas

Micro Combined Heat and Power

Micro Combined Cooling Heating and Power 


\begin{tabular}{ll} 
MFH & Multifamily House \\
PS & Proposed System \\
TS & Traditional System \\
Subscripts & \\
B & boiler \\
CHP & Combined Heat and Power \\
EGHE & Exhaust Gas Heat Exchanger \\
el & electric \\
in & inlet \\
loss & losses \\
MCHP & Micro Combined Heat and Power \\
out & outlet \\
p & primary \\
r & return \\
ref & reference \\
s & supply \\
th & thermal \\
Superscripts & \\
CV & Control Volume \\
PS & Proposed System \\
SH & Space Heating \\
TS & Traditional System \\
Referencs & \\
\hline &
\end{tabular}

\section{References}

Angrisani, G., Roselli, C., Sasso, M., \& Tariello F. (2014). Dynamic performance assessment of a micro-trigeneration system with a desiccant-based air handling unit in Southern Italy climatic conditions, Energy Conversion and Management, 80, 188-201. http://dx.doi.org/10.1016/j.enconman.2014.01.028

Angrisani, G., Roselli, C., \& Sasso M. (2012). Distributed microtrigeneration systems, Progress in Energy and Combustion Science, 38,502-521. http://dx.doi.org/10.1016/j.pecs.2012.02.001

Arndt, U., Beausoleil-Morrison, I., Davis, M., Dorer, V., Entchev, E., Ferguson, A., ... Swinton, M. (2007). Experimental Investigation of Residential Cogeneration Devices and Calibration of Annex 42 Models, A Report of Subtask B of FC+COGEN-SIM, The Simulation of Building-Integrated Fuel Cell and Other Cogeneration Systems, Annex 42 of the International Energy Agency. http://www.ecbcs.org/docs/Annex_42_Experiments_\&_Model_Calibration.pdf

Arndt, U., Mauch, W., Mühlbacher, H., Tzscheutschler, P., \& Geiger, B. (2008). Performance of Residential Cogeneration Systems in Germany, A Report of Subtask C of FC+COGEN-SIM, The Simulation of Building-Integrated Fuel Cell and Other Cogeneration Systems, Annex 42 of the International Energy Agency. http://www.ecbcs.org/docs/Annex_42_Performance_of_Residential_Cogeneration_Systems_in_Germany.pdf

Commission Decision of 21 December 2006 establishing harmonised efficiency reference values for separate production of electricity and heat in application of Directive 2004/8/EC of the European Parliament and of the Council (2006), document number C 6817, Official Journal of the European Union, 2007. http://eur-lex.europa.eu/legal-content/EN/TXT/PDF/?uri=CELEX:32007D0074\&qid=1405422588818\&from=EN

Commission implementing decision of 19 December 2011 establishing harmonised efficiency reference values for separate production of electricity and heat in application of Directive 2004/8/EC of the European Parliament and of the Council and repealing Decision 2007/74/EC, 2011. http://eur-lex.europa.eu/legal-content/EN/TXT/PDF/?uri=CELEX:32011D0877\&qid=1405422588818\&from=EN

Directive 2004/8/EC of the European Parliament and of the Council of the 11 February 2004 on the promotion of cogeneration based on the useful heat demand in the internal energy market and amending Directive 92/42/ EEC, 


Official Journal of the Union, 2004.

http://eur-lex.europa.eu/legal-content/EN/TXT/PDF/?uri=CELEX:32004L0008\&qid=1405422805569\&from=EN

Pehnt, M., Cames, M., Fischer, C., Praetorius, B., Schneider, L., Schumacher, K., \& Voß, J. P. (2006). Micro cogeneration: towards decentralized energy systems. Nederland: Springer.

Piacentino, A., \& Cardona, F. (2008). An original multi-objective criterion for the design of small-scale polygeneration systems based on realistic operating conditions, Applied Thermal Engineering, 28, 2391-2404. http://dx.doi.org/10.1016/j.applthermaleng.2008.01.017

Roselli, C., Sasso, M., Sibilio, S., \& Tzscheutschler, P. (2011). Experimental analysis of microcogenerators based on different prime movers, Energy and Buildings, 43,796-804. http://dx.doi.org/10.1016/j.enbuild.2010.11.021

TRNSYS 17, a TRaNsient SYstem Simulation program, Solar Energy Laboratory, University of Wisconsin-Madison, 2010. http://sel.me.wisc.edu/trnsys/

\section{(cc) $E_{Y}$}

This work is licensed under a Creative Commons Attribution 3.0 License. 